\title{
ESTRATÉGIAS LÚDICAS NO CUIDADO COM A CRIANÇA HOSPITALIZADA: PERSPECTIVAS SIMBÓLICAS DE DISCENTES DE ENFERMAGEM
}

\author{
PLAYFUL STRATEGIES IN THE CARE OF \\ HOSPITALIZED CHILDREN: SYMBOLIC \\ PERSPECTIVES OF NURSING STUDENTS
}

\section{ESTRATEGIAS LÚDICAS EN EL CUIDADO DE NIÑOS HOSPITALIZADOS: PERSPECTIVAS SIMBÓLICAS DE LOS ESTUDIANTES DE ENFERMERÍA}

\author{
Isabella Camargo Tannos Ferreira de Sá ${ }^{1}$ \\ Jessica Renata Bastos Depianti ${ }^{2}$ \\ Juliana Maria Rego Maciel Cardoso ${ }^{3}$ \\ Laura Johanson da Silva ${ }^{4}$ \\ Italo Rodolfo Silva \\ Thiago Privado da Silva ${ }^{6}$
}

Como citar este artigo: Sá ICTF, Depianti JRB, Cardoso JMRM, Silva LJ, Silva IR, Silva TP. Estratégias lúdicas no cuidado com a criança hospitalizada: perspectivas simbólicas de discentes de enfermagem. Rev baiana enferm. 2021;35:e45416.

Objetivo: compreender os significados e os fatores intervenientes relativos ao uso de estratégias lúdicas no cuidado com a criança hospitalizada na perspectiva de discentes de enfermagem. Método: pesquisa qualitativa realizada com 17 discentes de enfermagem. Os dados foram coletados entre outubro de 2020 e março de 2021, sendo submetidos à análise temática de conteúdo e interpretados à luz do Interacionismo Simbólico. Resultados: os temas "Atribuindo Significados ao Lúdico" e "Fatores Intervenientes para o Desenvolvimento do Lúdico" revelaram as significações simbólicas das estratégias lúdicas para o cuidado dispensado à criança hospitalizada e os fatores intervenientes, a saber: disponibilidade de recursos humanos e materiais, rotina e burocracia institucional, capacitação e empenho dos profissionais e envolvimento do familiar. Considerações finais: compreendeu-se que as perspectivas simbólicas dos discentes determinaram as estratégias lúdicas como um recurso extremamente importante nas relações de cuidado com a criança hospitalizada e sua utilização está condicionada aos fatores intervenientes expostos.

Descritores: Jogos e Brinquedos. Criança Hospitalizada. Estudantes de Enfermagem. Educação Superior. Enfermagem Pediátrica.

\footnotetext{
Enfermeira. Pesquisadora Independente. Macaé, Rio de Janeiro, Brasil. https://orcid.org/ 0000-0003-4478-3986.

Enfermeira. Mestre em Enfermagem. Escola de Enfermagem Anna Nery da Universidade Federal do Rio de Janeiro. Rio de Janeiro, RJ, Brasil. https://orcid.org/0000$0002-9157-3159$.

Enfermeira. Doutora em Enfermagem. Professora Adjunto do Centro Multidisciplinar da Universidade Federal do Rio de Janeiro. Macaé, Rio de Janeiro, Brasil. https://orcid.org/0000-0003-4082-4533.

4 Enfermeira. Doutora em Enfermagem. Professora Adjunto da Escola de Enfermagem Alfredo Pinto. Rio de Janeiro, RJ, Brasil. https://orcid.org/0000-0002-4439-9346. 5 Enfermeiro. Doutor em Enfermagem. Professor Adjunto do Centro Multidisciplinar da Universidade Federal do Rio de Janeiro. Macaé, Rio de Janeiro, Brasil. https://orcid.org/0000-0002-2882-1877.

6 Enfermeiro. Doutor em Enfermagem. Professor Adjunto do Centro Multidisciplinar da Universidade Federal do Rio de Janeiro. Macaé, Rio de Janeiro, Brasil. thiagopsilva87@gmail.com. https://orcid.org/0000-0002-7744-8319.
} 
Objective: to understand the meanings and intervening factors related to the use of playful strategies in the care of hospitalized children from the perspective of nursing students. Method: qualitative research conducted with 17 nursing students. Data were collected between October 2020 and March 2021, being submitted to thematic content analysis and interpreted in the light of Symbolic Interactionism. Results: the themes "Attributing Meanings to Play" and "Intervening Factors for the Development of Play" revealed the symbolic meanings of playful strategies for the care provided to hospitalized children and the intervening factors, namely: availability of human and material resources, routine and institutional bureaucracy, training and commitment of professionals and involvement of the family member. Final considerations: it was understood that the symbolic perspectives of the students determined the playful strategies as an extremely important resource in the relationships of care with hospitalized children and their use is conditioned to the intervening factors exposed.

\section{Descriptors: Play and Playtings. Child Hospitalized. Students, Nursing. Education, Higher. Pediatric Nursing.}

Objetivo: comprender los significados y factores intervinientes relacionados con el uso de estrategias lúdicas en el cuidado de niños hospitalizados desde la perspectiva de los estudiantes de enfermería. Método: investigación cualitativa realizada con 17 estudiantes de enfermería. Los datos fueron recolectados entre octubre de 2020 y marzo de 2021, siendo sometidos a análisis de contenido temático e interpretados a la luz del Interaccionismo Simbólico. Resultados: los temas "Atribuir significados al juego" y "Factores intervinientes para el desarrollo del juego" revelaron los significados simbólicos de las estrategias lúdicas para la atención prestada a los niños hospitalizados $y$ los factores intervinientes, a saber: disponibilidad de recursos humanos y materiales, burocracia rutinaria e institucional, capacitación y compromiso de los profesionales e implicación del familiar. Consideraciones finales: se entendió que las perspectivas simbólicas de los estudiantes determinaron las estrategias lúdicas como un recurso sumamente importante en las relaciones de atención con los niños hospitalizados y su uso está condicionado a los factores intervinientes expuestos.

Descriptores: Juego e Implementos de Juego. Niño Hospitalizado. Estudiantes de Enfermería. Educación Superior. Enfermería Pediátrica.

\section{Introdução}

A utilização de estratégias lúdicas nas relações com a criança apresenta-se como importante demanda para a família e para profissionais da educação e saúde, haja vista o seu positivo impacto no desenvolvimento cognitivo, físico, afetivo e social $^{(1)}$. No âmbito do cuidado em saúde, ressalta-se que vários recursos lúdicos podem ser utilizados nas relações com a criança, quais sejam: brinquedoteca, brinquedo terapêutico, musicoterapia, ambiente decorado, arteterapia, jogos, livros de história, terapia assistida por animais, fantoches e dramatização ${ }^{(1-2)}$.

Considerando a realidade da criança hospitalizada, a literatura destaca a importância do lúdico no cuidado em saúde. O processo de hospitalização constitui-se como uma experiência traumática e estressante, sobretudo para o público infantil, uma vez que implica em mudanças nos hábitos de vida diária, afastamento do convívio familiar e social, sentimentos de medo, necessidade de adaptação temporária ou permanente ao desconhecido, sendo permeado por restrições e rotinas preestabelecidas. Além disso, ela possui um número limitado de mecanismos para enfrentamento dessas situações que são atípicas para sua idade ${ }^{(3)}$.

Por essa razão, é importante que os profissionais de saúde desenvolvam competências para o uso de estratégias lúdicas no cuidado com a criança hospitalizada, tendo em vista os benefícios do brincar apontados pela literatura científica, que ajudam no desenvolvimento cerebral, quais sejam: fornecimento de recursos cognitivos, oportunidades de aprendizagens e avanços no âmbito emocional, interpessoal, linguagem e autorregulação ${ }^{(1,4)}$.

Nessa conjuntura, a literatura registra que o lúdico nos cuidados de enfermagem pode ser empregado com múltiplas finalidades e benefícios, dentre os quais se destacam: estratégia de interação, facilitando a comunicação e o estabelecimento de vínculo com a criança e a família; avaliação e estratégia de analgesia não farmacológica no manejo da dor; promoção do 
bem-estar, redução da ansiedade, socialização, aceleração da recuperação e melhoria da adesão da criança ao tratamento ${ }^{(5)}$.

Ademais, nota-se que a valorização das atividades recreativas, nesse cenário, propicia a ação de simbolizar experiências prévias desagradáveis, tais como a dor, pois, por meio de tal ação, são construídos significados e é conhecido o imaginário infantil ${ }^{(5)}$. Sendo assim, admite-se que o lúdico deve constar no planejamento da assistência de enfermagem dirigida à criança nos diversos contextos de cuidado, em especial no cenário hospitalar, onde ela é submetida a uma nova rotina que envolve a realização de vários procedimentos por vezes dolorosos e traumatizantes para salvaguardar a sua vida.

Contudo, embora a literatura científica ${ }^{(2,4)}$ confirme os benefícios das estratégias lúdicas nas interações de cuidado com a criança hospitalizada, estudos ${ }^{(6-8)}$ apontam dificuldades da equipe de enfermagem em aplicar tais estratégias, por várias razões, entre as quais, cumpre destacar despreparo, insegurança, pouca valorização e conhecimento que esses profissionais apresentam diante da possibilidade de utilizar esse recurso. Avalia-se que esse fato pode estar associado à insuficiência do ensino da temática nos cursos de graduação em Enfermagem.

A esse respeito, estudo $^{(9)}$ ressalta a imperatividade de enfermeiros reconhecerem, nas relações de cuidado, as vantagens e influências do lúdico desde a sua formação. Esta deve ser baseada em metodologias de ensino exploratórias, com vistas à difusão e incorporação das diversas modalidades lúdicas na assistência humanizada de enfermagem à criança. Para este fim, é premente que os docentes estejam atentos à importância do tema no processo de formação do enfermeiro e dos demais profissionais de enfermagem, construindo com eles, mediante o processo de ensino-aprendizagem, interações simbólicas capazes de nortear a imersão de significados de valorização das estratégias lúdicas.

Nesse sentido, entende-se que essas estratégias devem não só fazer parte de conteúdos teóricos das disciplinas de Enfermagem Pediátrica como também devem ser inseridas na prática de ensino e nos estágios relacionadas a essa área de conhecimento. É imprescindível possibilitar aos discentes o desenvolvimento de competências ética, técnica e subjetiva no emprego desses recursos.

Destaca-se que a literatura sobre o tema tem focado na perspectiva dos familiares, da criança e dos profissionais de enfermagem acerca do uso dessas estratégias no contexto hospitalar, em especial, quando se refere ao brinquedo terapêutico $^{(3,6,9)}$. Por essa razão, a relevância deste estudo repousa na possibilidade de conhecer a perspectiva simbólica de discentes de enfermagem sobre o uso de estratégias lúdicas no cuidado com a criança hospitalizada.

Desse modo, questiona-se: Quais significados e fatores intervenientes estão relacionados ao uso de estratégias lúdicas no cuidado dispensado à criança hospitalizada na perspectiva de discentes de enfermagem? Objetivou-se, portanto, compreender os significados e os fatores intervenientes relativos ao uso de estratégias lúdicas no cuidado com a criança hospitalizada na perspectiva de discentes de enfermagem.

\section{Método}

Trata-se de um estudo descritivo de abordagem qualitativa que utilizou o Interacionismo Simbólico como referencial teórico. Compreende-se que o uso de estratégias lúdicas no cuidado com a criança hospitalizada é determinado pelo significado que os discentes atribuem às suas interações sociais com a criança, de onde percebe, interpreta e reage de modo consciente no processo interativo ${ }^{(10)}$.

Participaram da pesquisa 17 discentes matriculados do $8^{\circ}$ ao $10^{\circ}$ período do Curso de Enfermagem de uma Universidade Federal localizada no estado do Rio de Janeiro. Cumpre esclarecer que a grade curricular do referido curso possibilita ao discente a vivência do cuidado de enfermagem dirigido à criança hospitalizada apenas no $7^{\circ}$ período da graduação, mediante a oferta de disciplina cujo foco é o cuidado de enfermagem. A carga horária é teórico-prática, contabilizando 45 e 150 horas, respectivamente, para média/alta complexidade, perpassando os cenários de Clínica Médica, Clínica Cirúrgica, 
Unidade de Terapia Intensiva e Unidade de Internação Pediátrica.

Para tanto, foram definidos os seguintes critérios de inclusão: ter concluído a supracitada disciplina e estar matriculado em disciplinas do $8^{\circ}$ ao $10^{\circ}$ período do Curso de Enfermagem. Utilizou-se como critério de exclusão estar afastado por licença médica ou por trancamento de matrícula na ocasião da coleta de dados.

Tendo em vista o atual cenário da COVID-19 e o momento atípico ocasionado pela pandemia, a coleta de dados aconteceu em encontros virtuais possibilitados pela plataforma GoogleMeet. A técnica de coleta de dados utilizada neste estudo consistiu na entrevista semiestruturada, gravada por meio digital. As entrevistas foram aplicadas no período compreendido entre outubro de 2020 e março de 2021, mediante um prévio contato por e-mail com o potencial participante, para esclarecimento dos seguintes pontos: proposta do estudo, riscos e benefícios de sua participação. Diante da concordância e da disponibilidade do participante em contribuir com a pesquisa, foi agendado o dia e o horário para a realização.

As entrevistas foram orientadas por um roteiro semiestruturado constituído por uma breve caracterização dos participantes, com vistas à avaliação do perfil desse público e à aproximação do pesquisador com os entrevistados, e contemplou as seguintes variáveis: nome, sexo, idade, período que estava cursando no momento da entrevista e vinculação a projeto de extensão que considerasse o público infantil. Ademais, a entrevista foi norteada pela seguinte questão de pesquisa: Que significados você atribui à utilização de estratégias lúdicas no cuidado dispensado à criança hospitalizada?

Cumpre destacar que a finalização da coleta de dados ocorreu após o alcance dos objetivos propostos e a saturação dos dados. Considerou-se o entendimento de que os temas elaborados apresentavam densidade analítica, mediante repetição dos achados e não aparecimento de informações novas e relevantes. As entrevistas foram transcritas na íntegra e submetidas à modalidade temática Análise de Conteúdo, em consonância com as suas respectivas etapas: pré-análise, exploração do material, tratamento dos resultados obtidos e interpretação ${ }^{(11)}$.

Na pré-análise, houve a preparação para a análise propriamente dita do material a ser investigado, ocorrendo uma primeira aproximação com o conteúdo das entrevistas, inicialmente, por meio da leitura "flutuante" dos dados brutos obtidos na coleta, sendo considerados, a priori, todos os elementos presentes nas falas dos participantes. Na etapa seguinte, exploração do material, os dados brutos foram analisados e codificados linha por linha, gerando as unidades de significação ${ }^{(11)}$. A terceira e última etapa de análise consistiu no tratamento dos resultados e interpretação. Nessa etapa, as unidades de significação foram submetidas à análise comparativa por similaridades e diferenças, sendo, então, organizadas em temas, que possibilitaram a avaliação e a interpretação final dos resultados ${ }^{(11)}$.

A presente pesquisa atendeu ao disposto na Resolução n. 466/2012 do Conselho Nacional de Saúde, respeitando todos os aspectos nela contidos. Foi submetida ao Comitê de Ética em Pesquisa (CEP) do Centro Multidisciplinar da Universidade Federal do Rio de Janeiro em Macaé e aprovada pelo Parecer $n^{\circ}$ 4.339.550, Certificado de Apresentação para Apreciação Ética (CAAE) 23152719.1.0000.5699. O Termo de Consentimento Livre e Esclarecido (TCLE) foi assinado pelos próprios discentes de enfermagem participantes do estudo, após receberem informações sobre riscos e benefícios de sua participação e enviado por e-mail ao pesquisador. Não foram conferidos ao TCLE ônus ou bônus. Assim, participaram do estudo, na condição de voluntários, com direito a desistência a qualquer momento. Os depoimentos dos participantes serão apresentados nos resultados e sua identificação será feita pela letra D seguida do número de ordem das entrevistas (D1, D2...), a fim de assegurar o anonimato.

\section{Resultados}

No tocante à caracterização dos participantes, houve o predomínio do público feminino, sendo apenas um do sexo masculino. Cumpre destacar que, do total de entrevistados, 
apenas seis estavam vinculados a projetos de extensão dedicados à temática infantil, a saber: aleitamento materno, cuidados com o recém-nascido/lactente, imunização infantil nas escolas, saúde do escolar, bem como o uso do lúdico no contexto hospitalar, especificamente, na Unidade de Internação Pediátrica. A faixa etária média dos entrevistados esteve entre 22 e 29 anos, à exceção de três voluntários, com idades de 30, 33 e 42 anos. No que tange ao quantitativo de discentes por período, durante o período da coleta de dados, 6 estavam no 8o período, outros 6 estavam no $9^{\circ}$ período e 5 estavam no $10^{\circ}$ e último período do curso.

Como resultado da análise, serão apresentados os seguintes temas: Atribuindo Significados ao Lúdico e Fatores Intervenientes para o Desenvolvimento do Lúdico.

\section{Atribuindo Significados ao Lúdico}

Esse tema revela que as significações simbólicas relativas ao uso de estratégias lúdicas para o cuidado com a criança hospitalizada estavam relacionadas às contribuições, aos recursos e às estratégias de interação adotadas pelos discentes nas relações de cuidado com o público infantil. A esse respeito, os discentes atribuíram significado de importância ao uso do lúdico, percebendo-o como estratégia de humanizar as relações de cuidado, pelo fato de possibilitar a construção de vínculos, a obtenção de confiança e a promoção de conforto. Adiante, algumas falas que corroboram o exposto:

Olha... eu penso que é de grande feito para a criança, para ela se sentir confortável no cuidado, enquanto está hospitalizada. Eu acho muito importante, principalmente porque as crianças entendem diferente dos adultos [...] (D1).

Eu acho extremamente importante o cuidado hídico com a criança hospitalizada. (D3).

Contribui para o vínculo do profissional com a criança e para o melhor enfrentamento do processo de hospitalização. O húdico não permite que ela tenha medo do profissional, fazendo com que ela se sinta mais à vontade e mais confortável. (D5).

Quando a gente fala de crianças, a gente pensa em outras estratégias... Então, o lúdico é uma forma de cuidado humanizado, com enfoque na pediatria, através de brincadeiras. Isso faz a criança se sentir mais acolbida no âmbito hospitalar. (D14).
É uma forma de você ganhar a confiança da criança para realizar o cuidado, seja ele uma medicação ou um exame físico. (D15).

Nessa conjuntura, os discentes de enfermagem elaboravam significados relativos ao potencial terapêutico do lúdico, ao enfatizar seus benefícios na recuperação, comunicação e compreensão das emoções da criança hospitalizada.

Nesse caso, a adesão melhorou, porque a criança não
estava querendo deixar passar a sonda, chorando muito.
Aí, quando fizemos essa "mãozinha" com a luva inflada,
ela começou a rir, facilitando o procedimento. (D2).
E eu acredito que as estratégias lúdicas, além de facilitar
o entendimento, prendem a atenção das crianças. Elas
fazem com que a gente consiga transmitir a mensagem
de forma muito mais a caráter da linguagem deles e de
forma muito mais divertida. (D6).

Eu acho o lúdico positivo, principalmente no ambiente bospitalar, para distrair e ter atividades que envolvam essa criança, que torne o tratamento, vamos dizer, o mais terapêutico possível para ela, em todas as dimensões que a envolvem. Acho muito positivo e necessário. (D7).

E quando a gente vai para esse lado lúdico, é muito mais fácil você chegar na criança até para explicar, tentar entender um pouco a situação dela, o que ela está vivenciando. Tentar saber as emocões numa brincadeira lúdica, em algo que você talvez não perceberia em uma anamnese técnica comum. Então, isso influenciaria bastante na vida profissional, para você saber lidar melhor com a criança, com todas as suas emoções $e$ tudo mais. (D8).

E acaba ajudando na sua recuperação [...] porque a criança acaba criando uma confiança na gente através das estratégias lúdicas. (D10).

Os discentes de enfermagem também manifestaram significados relativos aos benefícios do lúdico para os familiares, conforme pontuado a seguir.

Ela [criança] fica ali sob uma situação de intenso estresse. Então, quando você leva o lúdico para elas, eu percebo um alivio dos pais [...] Principalmente, também na questão dos pais, eu percebo assim esse alivio, esse pequeno descansar deles. (D11).

A minha percepção é que elas [estratégias lúdicas] são necessárias, porque é uma forma de criar um vínculo com essa criança e também com os seus responsáveis. (D15).

Ao elencar as estratégias lúdicas implementadas nas relações de cuidado com a criança, os discentes revelaram usar, como recursos, brinquedos, luva inflada, jogos, música, vestimenta e materiais personalizados, maquiagem e desenhos, conforme exposto a seguir.

A gente, por orientação mesmo da professora, a gente levava algum bonequinho para brincar enquanto es- 
tava com a criança. Lembrávamos um pouco algumas músicas de infância, para poder brincar com a criança enquanto estivéssemos fazendo o atendimento ou acompanhando algum atendimento. (D1).

Eu passei a interagir de uma forma mais lúdica. Eu comecei a falar de super-heróis. Eu estava com um bonequinbo do Batman e comecei a interagir com aquela criança como se fosse o Batman interagindo. E aí consegui fazer tudo que eu precisava fazer, principalmente o exame físico. (D3).

Na nossa época, teve uma equipe, eu não lembro ao certo o nome, mas eles iam vestidos de princesa para poder divertir as crianças. No dia, teve até uma equipe vestida de personagens da Disney. (D7).

A gente ficava brincando, montando quebra-cabeça, fazendo alguma atividade. (D8).

Eu procuro implementar o lúdico, mas claro que acaba sendo mais fácil quando a gente vai lá como projeto [projeto de extensão], que a gente já vai com maquiagem e material, né? (D11).

Eu, enquanto discente, utilizei aqueles bichinhos que a gente faz com a luva [...] Toda aquela decoração mais colorida com os desenhos, tudo aquilo chama atenção da criança. (D12).

Além do lúdico, os discentes utilizaram outras estratégias de ação e interação com a criança hospitalizada. Nessa conjuntura, estabelecer uma relação de cuidado baseada na empatia, no diálogo e na afetividade pareceu-lhes configurar-se como possibilidade de criar e fortalecer vínculos no processo interativo.

\begin{abstract}
Acho que tem um significado muito profundo você trabalhar com criança, saber compreender muitas coisas para além da saúde. É você saber se colocar no lugar da criança. Uma questão de entender melhor o que se passa na cabeça dela, porque não é um adulto que você está atendendo. (D9).
\end{abstract}

Quando estava estagiando, eu fiz os cuidados que a gente faz como se fosse um adulto, só que com um pouco mais de fofura e de atenção. (D14).

E com as crianças maiores, o que eu tentava fazer era conversar. Às vezes, a criança estava com uma boneca. E eu conversava: "Nossa, que linda sua boneca! Ela tem um nome?" Tentar desenvolver assim uma conversa, um diálogo com a criança [...] Então, eu tentava dialogar com a criança, para criar esse vínculo e conseguir realizar os cuidados que ela precisava. (D17).

\section{Fatores Intervenientes para o}

Desenvolvimento do Lúdico

No percurso das interações simbólicas de cuidado com a criança hospitalizada, os discentes perceberam a existência de fatores intervenientes para o desenvolvimento do lúdico nas relações de cuidado. Sob essa perspectiva, o tema Fatores Intervenientes para o Desenvolvimento do Lúdico faz menção aos fatores condicionantes à implementação das estratégias lúdicas, isto é, apresenta as condições que influenciam de modo positivo e/ou negativo o desenvolvimento dessas no contexto da hospitalização infantil.

Diante do exposto, no tocante às dificuldades encontradas para implementação do lúdico na percepção dos discentes, destacaram-se: a rotina e a burocracia institucional, o pouco tempo dos profissionais de saúde em interagir com a criança, a sobrecarga de trabalho relacionada ao déficit de recursos humanos e materiais, a escolha acertada da estratégia lúdica, considerando a faixa etária da criança, a pouca familiaridade dos profissionais com o tema e, por último, o pouco envolvimento dos familiares no desenvolvimento dessa prática.

\footnotetext{
Os profissionais estão presos numa rotina sistemática, tão mecânica que é um pouco difícil quebrar essa barreira. É um trabalho que tem de ser feito continuamente, para que isso se torne uma prática diária. Então, tem essa dificuldade, porque eles estão lá tão fixados numa rotina, que, quando você quebra essa rotina, leva um bom tempo para as pessoas assimilarem. (D1).

O que eu acho que pode dificultar é a questão do próprio serviço de saúde mesmo, às vezes por protocolos ou regimento interno da unidade, que às vezes não dê tanta liberdade para o profissional atuar da forma que queira. (D4).
}

O que pode dificultar seria a sobrecarga de trabalbo e a falta de recursos. Eu quase não vejo no hospital os recursos materiais e humanos. E ausência de pessoas especializadas nessa área também, assim como o quantitativo de profissionais. (D5)

Eu acho que o que pode dificultar, por parte do profissional de saúde, talvez seja o tempo que ele tem para isso. Porque a gente sabe como é corrido no setor. Então, como ele teria tempo hábil para aquela criança? (D8).

Também tem a questão da faixa etária. Nem sempre você vir com o brinquedo vai dar certo. A depender da idade. (D9).

E o que dificulta a aplicabilidade das estratégias lúdicas é a capacitação, porque acredito que não tenha. Então, os profissionais não estão preparados para fazer a aplicabilidade das estratégias para a criança. (D10).

Muitos pais podem não entender essa metodologia [lúdico] [...] E isso dificultaria. (D12).

Em contrapartida, os discentes elencaram como fatores facilitadores para a implementação do lúdico no cuidado dispensado à criança 
hospitalizada, as seguintes condições: a disponibilidade de materiais, a capacitação profissional sobre o tema, a participação efetiva do familiar, bem como o empenho individual e coletivo dos profissionais de saúde. As falas a seguir são ilustrativas:

O que poderia facilitar o uso do lúdico? Eu acho que o material. Se a instituição tivesse esse material, que pudesse ser utilizado nesse momento de interação com a criança, eu acredito que esse momento seria facilitado. (D3).

Eu acho que uma educação continuada para os profissionais de saúde facilitaria, porque, para muitos deles, não foi nem ensinado o húdico. (D6).

Acho que o que pode facilitar o uso do húdico é o profissional empenhado em querer utilizar o brinquedo como estratégia lúdica. (D9).

Então, assim, quando a equipe como um todo entende a importância desse lúdico, ela também participa [...] é um fator muito positivo para a criança. (D11).

O que eu acho que pode facilitar é incluir também os responsáveis nessas estratégias lúdicas; trazer os pais, quando realizar alguma brincadeira / dinâmica com a criança; trazer os responsáveis para participar. (D15).

\section{Discussão}

Os resultados da pesquisa revelaram que, dentre os significados atribuídos ao uso de estratégias lúdicas pelos discentes de enfermagem, se destaca a sua importância enquanto uma estratégia de humanização do cuidado com a criança hospitalizada. Em consonância com o exposto, estudos ressaltam as brincadeiras e o uso de brinquedo terapêutico como importantes atividades no contexto hospitalar pediátrico, pois possibilitam uma assistência de qualidade à criança e sua família, ao tornar o cuidado de enfermagem mais humanizado ${ }^{(12-13)}$. Assim, o lúdico configura-se como um recurso válido e de extrema relevância, ao potencializar a satisfação do público infantil e seus familiares com a prestação da assistência de enfermagem ${ }^{(14)}$.

Nas interações simbólicas, os discentes de enfermagem realizavam interpretações relativas ao uso do lúdico, desenvolviam uma consciência sobre seus benefícios e atribuíam um significado a esse fenômeno ${ }^{(11)}$. Quanto aos benefícios das estratégias lúdicas apontados pelos discentes, destacaram-se: comunicação, construção de vínculo e confiança entre o profissional e a criança, atenuação de medos e inseguranças, promoção de conforto, entretenimento, potencial terapêutico, bem como uma estratégia para a compreensão das emoções da criança hospitalizada. A esse respeito, estudo de revisão sistemática ${ }^{(15)}$ ratifica as contribuições do lúdico no processo de hospitalização infantil, ao ressaltar que o recurso de analgesia não farmacológica minimiza sentimentos como ansiedade, insegurança e medo e aumenta a confiabilidade nos profissionais de saúde, para maior aceitação das intervenções. Assim, assumem uma postura mais colaborativa.

Desse modo, compreende-se que a brincadeira não se traduz em uma superficialidade, tendo em vista os benefícios proporcionados à criança, na perspectiva cognitiva, psicossomática, do equilíbrio emocional, da linguagem e da socialização, possibilitando-lhes desenvolver a noção de negociação e cooperação ${ }^{(1)}$. Nessa conjuntura, o brinquedo terapêutico surge como importante recurso para o cuidado com a criança hospitalizada, ao possibilitar-lhe que expresse seus sentimentos e compreenda os procedimentos aos quais será submetida. Com isso, capacita uma função fisiológica que precisa ser potencializada $^{(13)}$. Nessa lógica, uma pesquisa bibliográfica designa o brincar como um recurso de ação terapêutica, ao amenizar a ociosidade do ambiente hospitalar. Pode, inclusive, reduzir o tempo de permanência nesse cenário, ao concorrer para o desenvolvimento físico e mental da criança no transcurso da doença ${ }^{(2)}$.

Sendo assim, o lúdico configura-se como uma ferramenta que otimiza os aspectos psicológicos, ao reduzir níveis de medo e ansiedade, ajudar na comunicação e nas estratégias de enfrentamento, além de elevar a autoestima. Por esse olhar, compreende-se que as significações sociais relativas ao uso do lúdico no contexto hospitalar são resultados da atribuição de valor e sentidos positivos à sua implementação. Estudo $^{(16)}$ conduzido em Hong Kong revela que crianças hospitalizadas que receberam intervenções lúdicas apresentaram menos emoções negativas e menor nível de ansiedade quando comparadas com crianças que receberam cuidado usual. 
Os autores desse estudo reforçam a importância de incorporar as intervenções lúdicas no cenário hospitalar, para prover um cuidado holístico e de qualidade à criança como possibilidade de aliviar sua carga psicológica. Em outro ângulo, ressalta-se que o brincar configura-se como uma janela por meio da qual o desenvolvimento de uma criança pode ser observado. Ao explorar os seus perfis de brincadeiras, é possível notar qual área do seu desenvolvimento pode estar $\operatorname{afetada}^{(17)}$.

$\mathrm{Na}$ perspectiva simbólica dos discentes de enfermagem, o lúdico pode proporcionar aos pais/cuidadores sentimentos de alívio e descanso. Tal significação pode motivar condutas que favoreçam o uso do lúdico no cuidado com a criança hospitalizada. Sob essa perspectiva, estudo aponta valorização das mães quanto ao uso do brinquedo terapêutico no contexto da emergência pediátrica, tendo em vista a redução do estresse. Ao minimizar a postura de resistência da criança e promover maior segurança, tranquilidade e bem-estar ao binômio mãe-criança, concorre para o fortalecimento do vínculo e a otimização no relacionamento entre esses e os profissionais de saúde envolvidos no cuidado ${ }^{(6)}$.

Dentre as estratégias lúdicas utilizadas pelos discentes entrevistados durante os encontros com a criança, distinguem-se: brinquedos, luva inflada, jogos, música, vestimenta e materiais personalizados, maquiagem e desenhos. Assim, na interação simbólica com a criança hospitalizada, eles lançavam mão da criatividade de modo consciente, para proporcionar diferentes tipos de brincadeiras que pudessem ser incluídas nesse contexto de cuidado. A esse respeito, estudo aponta diversas abordagens lúdicas, tais como jogos, brincadeiras, contação de histórias e desenhos livres, as quais se constituem em instrumento terapêutico, revelando-se como recurso de distração para o público infantil diante do impacto biopsicossocial ocasionado pela hospitalização ${ }^{(9)}$.

O uso de fantoches também se mostra como uma brincadeira eficaz, ao compreender a percepção das crianças no que tange ao entendimento acerca da sua condição de saúde, bem como as experiências vivenciadas por elas no ambulatório. Com isso, permite uma sistematização da assistência de enfermagem e considera as especificidades do universo infantil ${ }^{(18)}$. No que diz respeito ao brinquedo terapêutico, a sua manipulação durante as sessões lúdicas desperta a criatividade e o imaginário infantil, aumenta a compreensão e familiariza-a com os procedimentos. Ao permitir a reprodução desses em bonecos, bem como a criação de novos significados, converge para uma resiliência com vistas a promover um cuidado atraumático ${ }^{(19)}$.

Adiante, a visitação pediátrica com vestimentas personalizadas de super-heróis, a exemplo do Batman, Super-Homem e Homem-Aranha, configura-se uma potente estratégia lúdica, visando amenizar os impactos da hospitalização infantil, haja vista a representatividade simbólica desses personagens. De modo semelhante, a palhaçoterapia, caracterizada como a terapia do riso, auxilia no processo de adaptação ao ambiente hospitalar, tornando-o menos aversivo. Propicia também melhoras do ponto de vista fisiológico, comportamental e emocional $^{(20)}$.

No processo interativo com a criança hospitalizada, os discentes lançavam mão de tecnologias leves de cuidado, como o diálogo, a empatia e o afeto, que, de acordo com a literatura para além do lúdico, destacam-se como estratégias de interação com esse público no manejo da dor oncológica crônica $^{(21)}$.

Nas interações sociais, o diálogo apresenta-se como importante elemento da linguagem e permite perceber, interpretar e elaborar significados que conduzem o comportamento humano ${ }^{(11)}$. A empatia, por sua vez, é entendida como a capacidade que permite o compartilhamento de experiências, necessidades, desejos, percepção e compreensão da perspectiva das emoções do outro ${ }^{(22)}$. Portanto, a empatia, o diálogo e o afeto, por suas relevâncias, devem permear os processos interativos de cuidado com a criança como importantes ferramentas relacionais de acolhimento.

Pôde-se inferir como dificuldades apresentadas pelos discentes para implementação do lúdico: a rotina e a burocracia institucional, o 
fator temporal frente ao baixo quantitativo de profissionais para uma intensa demanda de cuidados, a escassez de recursos materiais, a assertividade na estratégia lúdica adotada compatível com a faixa etária da criança, o contato superficial dos profissionais com a temática em questão e a pouca participação da família durante o desenvolvimento das estratégias lúdicas. Por outro lado, os discentes elencaram, como fatores facilitadores para a inserção do lúdico no cuidado com a criança hospitalizada, o fornecimento de materiais compatíveis com a idade da criança, a capacitação profissional, a real participação da família e, ainda, o comprometimento dos profissionais de saúde.

A interpretação de fatores como facilitadores e dificultadores para o uso do lúdico no cuidado com a criança hospitalizada estava condicionada pelas interações sociais simbólicas estabelecidas pelos discentes, ao desenvolverem o cuidado de enfermagem com a criança. Partindo da premissa que os significados são manipulados e modificados por meio de um processo interpretativo ${ }^{(11)}$, entende-se que essa significação é passível de mudanças no decurso do processo de cuidado.

Acerca do fornecimento de materiais adequados, capacitação e empenho profissional, a literatura ressalta a necessidade de materiais lúdicos, assim como profissionais qualificados e aptos a realizarem as atividades lúdicas nos contextos de cuidados com a criança. Além disso, destaca-se o empenho do profissional enfermeiro, o qual deve inserir o brincar no cuidado dispensado ao público infantil ${ }^{(9)}$.

A assertividade na escolha da estratégia lúdica a ser utilizada reforça a necessidade de capacitação dos profissionais de saúde sobre o tema, pelo fato de a criança aperfeiçoar sua linguagem e adquirir novas habilidades e interesses no percurso de suas zonas de desenvolvimento humano. Sob essa perspectiva, a literatura destaca que as crianças, à medida que crescem e desenvolvem formas mais complexas de brincar, tendem a desenvolver certas preferências relacionadas ao gênero na seleção de brinquedos, conforme facilitado pelo seu contexto social ${ }^{(23)}$.

Estudo revelou a inserção de estratégias lúdicas, por meio de jogos, como propulsoras para o envolvimento e engajamento da família, tornando-a coparticipante no que tange aos cuidados e segurança do pequeno paciente ${ }^{(24)}$. Sob essa perspectiva, pesquisa revelou que os progenitores compreendiam as estratégias lúdicas como condição facilitadora da adaptação da criança ao seu processo de hospitalização, ao permitir que a criança redirecionasse o foco dos procedimentos dolorosos para o brincar. Assim, propiciava um momento de descontração e, por conseguinte, resgatava a sua essência de criança $^{(25)}$.

Os resultados da pesquisa realizada são relevantes para o avanço da Enfermagem Pediátrica, ao contribuírem com questões relacionadas ao ensino e ao uso do lúdico no cuidado com a criança hospitalizada. Todavia, admite-se como limitação deste estudo, o uso de apenas uma técnica de coleta de dados, não acontecendo uma triangulação de coleta e análise de dados. Ademais, há de se pontuar a impossibilidade de generalização estatística, uma característica dessa modalidade de pesquisa.

Em face do exposto, aponta-se para o direcionamento de novos estudos que objetivem compreender a perspectiva dos docentes, no tocante ao significado e às estratégias de ensino empregadas nos cursos de graduação em enfermagem sobre o tema em tela. Além disso, sugere-se também o desenvolvimento de pesquisas apoiadas em referenciais teóricos e metodológicos robustos, capazes de possibilitar um entendimento mais aprofundado sobre o tema, para fins de aplicação prática dos resultados nos diversos contextos em que são desenvolvidos os cuidados com a criança e sua família.

\section{Considerações Finais}

Dentre os recursos lúdicos utilizados pelos discentes que participaram da pesquisa, destacaram-se brinquedos, luva inflada, jogos, música, vestimenta e materiais personalizados, maquiagem e desenhos. Ademais, foram citadas outras estratégias de interação com a criança hospitalizada, com destaque para o uso de tecnologias relacionais, como a empatia, o diálogo e o afeto. 
No que se refere aos fatores limitadores para o uso do lúdico, os discentes destacaram a rotina e a burocracia institucional, o pouco tempo dos profissionais de saúde para interagir com a criança, a sobrecarga de trabalho relacionada ao déficit de recursos humanos e materiais, a escolha acertada da estratégia lúdica considerando a faixa etária da criança, a pouca familiaridade dos profissionais com o tema e o pouco envolvimento dos familiares no desenvolvimento dessa prática. Por outro lado, emergiram como fatores facilitadores, para o uso do lúdico, a disponibilidade de materiais, a capacitação profissional sobre o tema, a participação efetiva do familiar, bem como o empenho individual e coletivo dos profissionais de saúde.

Concluiu-se, com base nos resultados, que as perspectivas simbólicas dos discentes determinaram as estratégias lúdicas como um recurso extremamente importante nas relações de cuidado com a criança hospitalizada. O uso do lúdico foi significado como estratégia de humanizar as relações de cuidado, ao possibilitar a construção de vínculos, a obtenção de confiança e a promoção de conforto. Também foram elaborados significados relativos ao potencial terapêutico do lúdico, ao enfatizar seus benefícios na recuperação, comunicação e compreensão das emoções da criança hospitalizada.

\section{Colaborações:}

1 - concepção, projeto, análise e interpretação dos dados: Isabella Camargo Tannos Ferreira de Sá e Thiago Privado da Silva;

2 - redação do artigo e revisão crítica relevante do conteúdo intelectual: Isabella Camargo Tannos Ferreira de Sá, Jessica Renata Bastos Depianti, Juliana Maria Rego Maciel Cardoso, Laura Johanson da Silva, Ítalo Rodolfo Silva e Thiago Privado da Silva;

3 - aprovação final da versão a ser publicada: Isabella Camargo Tannos Ferreira de Sá, Jessica Renata Bastos Depianti, Juliana Maria Rego Maciel Cardoso, Laura Johanson da Silva, Ítalo Rodolfo Silva e Thiago Privado da Silva.

\section{Referências}

1. Yogman M, Garner A, Hutchinson J, Hirsh-Pasek K, Golinkoff RM. The Power of Play: A Pediatric Role in Enhancing Development in Young Children. Pediatrics. 2018;142(3):1-18. DOI: 10.1542/peds. 2018-2058

2. Sossela CR, Sager F. A criança e o brinquedo no contexto hospitalar. Rev SBPH [Internet]. 2017 [cited 2021 Jun 17];20(1):17-31. Available from: http://pepsic.bvsalud.org/pdf/rsbph/v20n1/ v20n1a03.pdf

3. Santos PM, Silva LF, Depianti JRB, Cursino EG, Ribeiro CA. Nursing care through the perception of hospitalized children. Rev Bras Enferm. 2016;69(4):646-53. DOI: 10.1590/0034$7167.2016690405 \mathrm{i}$

4. Salcuni S, Mazzeschi C, Capella C. Editorial: The Role of Play in Child Assessment and Intervention. Front Psychol. 2017;8:1098. DOI: 10.3389/fpsyg.2017.01098

5. Silva TP, Leite JL, Stinson J, Lallo C, Silva IR, Jibb L. Actions and interactions strategies for the care of hospitalized children with chronic cancer pain. Texto Contexto Enferm. 2018;27(4):e3990017. DOI: 10.1590/0104-07072018003990017

6. Berté C, Ogradowski KRP, Zagonel IPS, Tonin L, Favero L, Almeida Junior RL. Therapeutic toy in the context of pediatric emergency. Rev baiana enferm. 2017;31(3):e20378. DOI: 10.18471/rbe. v31i3.20378

7. Lima KYN, Barros AG, Costa TD, Santos VEP, Vitor AF, Lira ALBC. Play as a tool in nursing care for hospitalized children. Rev Min Enferm. 2014;18(3):741-6. DOI: 10.5935/ $1415-2762.20140054$

8. Oliveira CS, Maia EBS, Borba MIH, Ribeiro CA. Brinquedo terapêutico na assistência à criança: percepção de enfermeiros das unidades pediátricas de um hospital universitário. Rev Soc Bras Enferm Ped. 2015;15(1):21-30. DOI: 10.31508/1676-3793201500004

9. Sposito AMP, Garcia-Schinzari NR, Mitre RMA, Pfeifer LI, Lima RAG, Nascimento LC. O melhor da hospitalização: contribuições do brincar para o enfrentamento da quimioterapia. Av Enferm. 2018;36(3):328-37. DOI: 10.15446/av.enferm. v36n3.61319 
10. Charon JM. Symbolic Interactionism: An Introduction, An Interpretation, An Integration. 10th ed. Boston: Prentice Hall; 2010.

11. Minayo MCS. O desafio do conhecimento: pesquisa qualitativa em saúde. 14a ed. São Paulo: Hucitec; 2014.

12. Barreto LMSC, Maia EBS, Depianti JRB, Melo LL, Ohara CVS, Ribeiro CA. Giving meaning to the teaching of Therapeutic Play: the experience of nursing students. Anna Nery Rev Enferm. 2017;21(2):1-9. DOI: 10.5935/14148145.20170038

13. Silveira A, Picollo BM. Brinquedo Terapêutico na assistência à criança hospitalizada na vOZ das profissionais de enfermagem. Rev Espaço Ciênc Saúde. 2021;8(2):51-60. DOI: 10.33053/recs. v8i2.377

14. Teksoz E, Bilgin I, Madzwamuse SE, Oscakci AF. The impact of a creative play intervention on satisfaction with nursing care: a mixed-methods study. J Spec Pediatr Nurs. 2017;22(1):e121609. DOI: $10.1111 /$ jspn.12169

15. Godino-Iáñez MJ, Martos-Cabrera MB, SuleimanMartos N, Gomez-Urquiza JL, Vargas-Ramon K, Membrive-Jimenez MJ, et al. Play therapy as an intervention in hospitalized children: a systematic review. Healthcare (Basel). 2020;8(3):239. DOI: 10.3390/healthcare8030239

16. Sezici E, Ocakci AF, Kadioglu H. Use of play therapy in nursing process: a prospective randomized controlled study. J Nurs Scholarsh. 2017;49(2):162-9. DOI: 10.1111/jnu.12277

17. Munambah N, Cordier R, Speyer R, Toto S, Ramugondo EL. A systematic review comparing the play profiles of children with special health care needs with typically developing children. BioMed Res Int. 2020;2020:ID9582795. DOI: $10.1155 / 2020 / 9582795$

18. Leite ACAB, Alvarenga WA, Machado JR, Luchetta LF, Banca ROL, Sparapani VC, et al.
Children in outpatient follow-up: perspectives of care identified in interviews with puppet. Rev Gaucha Enferm. 2019;40:e20180103. DOI: 10.1590/1983-1447.2019.20180103

19. Fontes CMB, Oliveira ASS, Toso LA. Therapeutic toy in pediatric intensive therapy unit. Rev Enferm UFPE Online. 2017;11(7):2907-15. DOI: 10.5205/ reuol.11007-98133-3-SM.1107sup201712

20. Catapan SC, Oliveira WF, Rotta TM. Clown therapy in the hospital setting: a review of the literature. Ciênc Saúde Coletiva. 2019;24(9):341729. DOI: $10.1590 / 1413-81232018249.22832017$

21. Silva TP, Silva LJ, Ferreira MJC, Silva IR, Rodrigues BMRD, Leite JL. Contextual aspects related to nursing care management of the child with chronic cancer pain. Texto Contexto Enferm. 2018;27(3):e3400017. DOI: 10.1590/0104070720180003400017

22. Riess H. The science of empathy. J Patient Exp. 2017;4(2):74-7. DOI: 10.1177/2374373517699267

23. Todd BK, Fischer RA, Di Costa S, Roestorf A, Harbour K, Hardiman P, et al. Sex differences in children's toy preferences: A systematic review, meta-regression, and meta-analysis. Infant Child Dev. 2017;27(2):e2064. DOI: 10.1002/icd.2064

24. Gonçalves KMM, Costa MTTCA, Silva DCB, Baggio ME, Corrêa AR, Manzo BF. Ludic strategy for promoting engagement of parents and caregivers in the safety of pediatric patients. Rev Gaucha Enferm. 2020;41:e20190473. DOI: 10.1590/1983-1447.2020.20190473

25. Rockembach JA, Espinosa TA, Cecagno D, Elaine T, Cardoso DS. Inserção do lúdico como facilitador da hospitalização na infância: percepção dos pais. J Nurs Health. 2017;7(2):117-26. DOI: 10.15210/JONAH.V7I2.7646

Recebido: 15 de julho de 2021 Aprovado: 15 de setembro de 2021 Publicado: 5 de outubro de 2021

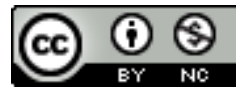

A Revista Baiana de Enfermagem utiliza a Licença Creative Commons - Atribuição-NãoComercial 4.0 Internacional. https://creativecommons.org/licenses/by-nc/4.0/ Este artigo é de acesso aberto distribuído sob os termos da Licença Creative Commons (CC BY-NC). Esta licença permite que outros remixem, adaptem e criem a partir do seu trabalho para fins não comerciais. Embora os novos trabalhos tenham de lhe atribuir o devido crédito e não possam ser usados para fins comerciais, os usuários não têm de licenciar esses trabalhos derivados sob os mesmos termos. 